\title{
Outdoor air pollution, exhaled 8-isoprostane and current asthma in adults: the EGEA study
}

\author{
Anaïs Havet ${ }^{1,2}$, Farid Zerimech ${ }^{3}$, Margaux Sanchez $^{4}$, Valérie Siroux ${ }^{5}$, \\ Nicole Le Moual ${ }^{1,2}$, Bert Brunekreef ${ }^{6,7}$, Morgane Stempfelet ${ }^{8}$, Nino Künzli, ${ }^{9,10}$, \\ Bénédicte Jacquemin ${ }^{1,2}$, Régis Matran ${ }^{11,12}$ and Rachel Nadif (1) $1,2,12$
}

Affiliations: ${ }^{1}$ INSERM U1168, VIMA (Aging and Chronic Diseases: Epidemiological and Public Health Approaches), Villejuif, France. ${ }^{2}$ Université Versailles St-Quentin-en-Yvelines, UMRS 1168, Montigny-leBretonneux, France. ${ }^{3}$ Pôle de Biologie Pathologie Génétique, Laboratoire de Biochimie et Biologie Moléculaire, CHU de Lille, Lille, France. ${ }^{4}$ ISGlobal, Centre for Research in Environmental Epidemiology, Universitat Pompeu Fabra, CIBER Epidemiología y Salud Pública, Barcelona, Spain. ${ }^{5}$ Equipe d'Epidémiologie Environnementale, Institute for Advanced Biosciences, Centre de Recherche UGA, INSERM U1209, CNRS UMR 5309, Grenoble, France. 'Institute for Risk Assessment Sciences, Utrecht University, Utrecht, The Netherlands. ${ }^{7}$ Julius Center for Health Sciences and Primary Care, University Medical Center Utrecht, Utrecht, The Netherlands. ${ }^{8}$ Santé Publique France, Saint-Maurice, France. ${ }^{9}$ Swiss Tropical and Public Health Institute, Basel, Switzerland. ${ }^{10}$ University of Basel, Basel, Switzerland. ${ }^{11}$ Université Lille and CHU de Lille, Lille, France. ${ }^{12}$ These authors are joint last authors.

Correspondence: B. Jacquemin, INSERM U1168, VIMA (Aging and Chronic Diseases: Epidemiological and Public Health Approaches), 16 avenue Paul Vaillant Couturier, 94807 Villejuif Cedex, France.

E-mail: benedicte.jacquemindinserm.fr

@ERSpublications

Exhaled 8-isoprostane concentration is associated with both outdoor air pollution and current asthma in adults http://ow.ly/esqN30iGCH3

Cite this article as: Havet A, Zerimech F, Sanchez M, et al. Outdoor air pollution, exhaled 8-isoprostane and current asthma in adults: the EGEA study. Eur Respir J 2018; 51: 1702036 [https://doi.org/10.1183/ 13993003.02036-2017].

ABSTRACT Associations between outdoor air pollution and asthma in adults are still scarce, and the underlying biological mechanisms are poorly understood. Our aim was to study the associations between 1) long-term exposure to outdoor air pollution and current asthma, 2) exhaled 8-isoprostane (8-iso; a biomarker related to oxidative stress) and current asthma, and 3) outdoor air pollution and exhaled 8-iso.

Cross-sectional analyses were conducted in 608 adults (39\% with current asthma) from the first followup of the French case-control and family study on asthma (EGEA; the Epidemiological study of the Genetic and Environmental factors of Asthma). Data on nitrogen dioxide, nitrogen oxides, particulate matter with a diameter $\leqslant 10$ and $\leqslant 2.5 \mu \mathrm{m}$ (PM10 and $\mathrm{PM} 2.5)$, road traffic, and ozone $\left(\mathrm{O}_{3}\right)$ were from ESCAPE (European Study of Cohorts for Air Pollution Effects) and IFEN (French Institute for the Environment) assessments. Models took account of city and familial dependence.

The risk of current asthma increased with traffic intensity (adjusted (a)OR 1.09 (95\% CI 1.00-1.18) per 5000 vehicles per day), with $\mathrm{O}_{3}$ exposure (aOR $2.04(95 \%$ CI $1.27-3.29)$ per $10 \mu \mathrm{g} \cdot \mathrm{m}^{-3}$ ) and with exhaled 8-iso concentration (aOR 1.50 (95\% CI 1.06-2.12) per $1 \mathrm{pg} \cdot \mathrm{mL}^{-1}$ ). Among participants without asthma, exhaled 8-iso concentration increased with PM2.5 exposure (adjusted (a) $\beta 0.23$ (95\% CI 0.005-0.46) per $\left.5 \mu \mathrm{g} \cdot \mathrm{m}^{-3}\right)$, and decreased with $\mathrm{O}_{3}$ and $\mathrm{O}_{3 \text {-summer }}$ exposures $(\mathrm{a} \beta-0.20(95 \% \mathrm{CI}-0.39--0.01)$ and a $\beta-0.52$ (95\% CI $-0.77--0.26)$ per $10 \mu \mathrm{g} \cdot \mathrm{m}^{-3}$, respectively).

Our results add new insights into a potential role of oxidative stress in the associations between outdoor air pollution and asthma in adults. 


\section{Introduction}

According to the World Health Organization, outdoor air pollution caused 3.7 million deaths globally in 2012 and 9\% of the total mortality in France was recently attributed to particulate matter with a diameter $\leqslant 2.5 \mu \mathrm{m}(\mathrm{PM} 2.5)$ [1]. The most studied pollutants in relation to health effects are nitrogen dioxide $\left(\mathrm{NO}_{2}\right)$, ozone $\left(\mathrm{O}_{3}\right)$, and particulate matter with a diameter $\leqslant 10 \mu \mathrm{m}(\mathrm{PM} 10)$ and PM2.5. Evidence of the impact of outdoor air pollution on respiratory health is increasing $[2,3]$, and the associations between exposure to outdoor air pollution and asthma have largely been studied in children [4]. However, studies on associations between long-term exposure to outdoor air pollution and asthma among adults are still carce [5].

One biological mechanism proposed to partly explain the association between outdoor air pollution and asthma is oxidative stress [6]. Oxidative stress is an imbalance between the increase in reactive oxygen species and antioxidant response [7]. Among the biological markers related to oxidative stress, 8 -isoprostane (8-iso; a prostaglandin $\mathrm{F}_{2}$-like compound belonging to the $\mathrm{F}_{2}$-isoprostane class) is known as a stable and specific product of lipid peroxidation [8]. Interestingly, 8-iso can be measured noninvasively in exhaled breath condensate (EBC) [7]. An increase of 8-iso concentration along with a decline of antioxidant defence can induce tissue damage and can contribute to pathophysiological changes such as those seen in asthma $[9,10]$. 8-iso is known to provoke airway hyperresponsiveness, to increase the production of mucus and to promote contraction of smooth muscles [10, 11]. In a recent systematic review, 8-iso concentration was found to be higher in adults with severe asthma than in those with mild-to-moderate asthma [12]. To date, epidemiological studies on the associations between long-term exposure to outdoor air pollution and asthma including the measurement of 8-iso in adults are lacking.

Here, among adults from the French EGEA (Epidemiological study of the Genetic and Environmental factors of Asthma) cohort, we first studied the associations between long-term exposure to outdoor air pollution $\left(\mathrm{NO}_{2}\right.$, nitrogen oxides $\left(\mathrm{NO}_{x}\right), \mathrm{PM} 10, \mathrm{PM} 2.5$, traffic load, traffic intensity, $\mathrm{O}_{3}$ and $\left.\mathrm{O}_{3 \text {-summer }}\right)$ and current asthma. Second, we studied the associations between 8-iso measured in EBC with both long-term exposure to outdoor air pollution and current asthma.

\section{Methods}

\section{Study population}

The EGEA is a cohort study based on an initial group of asthma cases recruited in chest clinics from five French cities (1991-1995) along with their first-degree relatives and a group of controls (https://egeanet.vjf. inserm.fr). Child controls were recruited from surgery hospitals, and adult controls from electoral rolls and from surgery hospitals or check-up centres [13]. The protocol and descriptive characteristics have been described previously [13, 14], and inclusion criteria used to define asthmatic cases and controls are described in the supplementary material. The EGEA collection is certified ISO 9001 [15]. Ethical approval was obtained from the relevant institutional review board committees (Cochin Port-Royal Hospital and Necker-Enfants Malades Hospital, Paris, France). All participants signed a written informed consent form.

The present analyses included 608 adults ( $\geqslant 16$ years old) in the framework of the first follow-up (EGEA2, 2003-2007), with available data on current asthma, outdoor air pollution assessed by ESCAPE (European Study of Cohorts for Air Pollution Effects) and exhaled 8-iso concentration (figure 1). Among the 608 participants, five had no pollution data from the IFEN (French Institute for the Environment) assessment. No significant differences were found between the participants included and those not included ( $\mathrm{n}=963$ ) (supplementary table E1).

\section{Respiratory phenotypes}

At EGEA2, the participants with ever-asthma answered positively to at least one of the two questions "Have you ever had attacks of breathlessness at rest with wheezing?" or "Have you ever had asthma attacks?", or were recruited as asthmatic cases at EGEA1.

Among participants with ever-asthma, "current asthma" was defined by a report of respiratory symptoms (wheeze, nocturnal chest tightness, attacks of breathlessness following strenuous activity, at rest or at night-time) or asthma attacks, or use of inhaled and/or oral medicines because of breathing problems in the past 12 months (see supplementary material for more details) [16]. Only participants with current asthma were included in the analyses because the phenotype "current asthma", which reflects the recent activity of the disease, was more relevant than the phenotype "ever-asthma" to study the associations between long-term exposure to outdoor air pollution, biological markers and asthma.

This article has supplementary material available from erj.ersjournals.com

Received: Oct 052017 | Accepted after revision: Feb 222018 


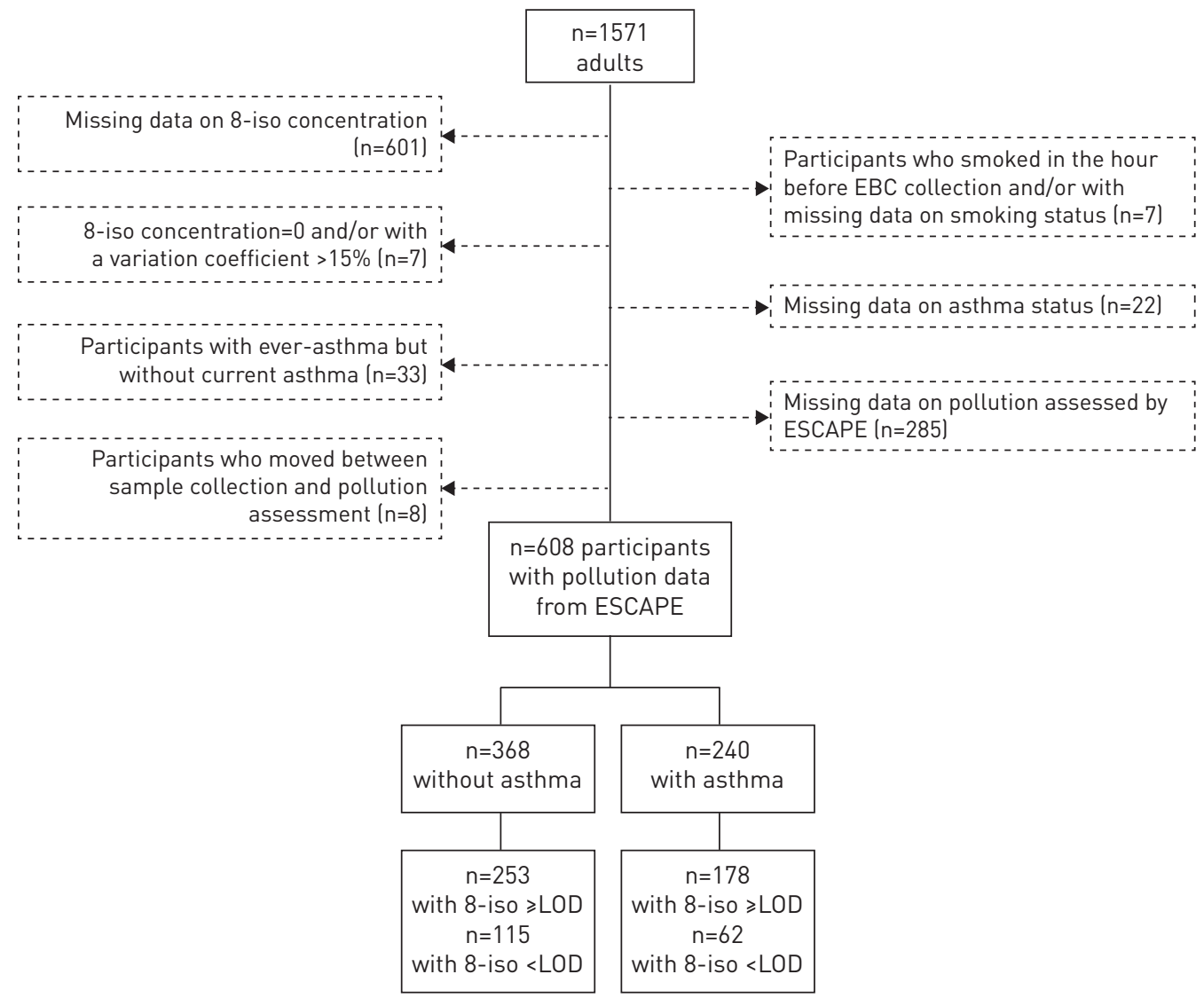

FIGURE 1 Flowchart of the studied population. 8-iso: 8-isoprostane; EBC: exhaled breath condensate; ESCAPE: European Study of Cohorts for Air Pollution Effects; LOD: limit of detection.

\section{Exposure assessment}

Using ESCAPE and IFEN assessments, outdoor air pollution exposures $\left(\mathrm{NO}_{2}, \mathrm{NO}_{x}\right.$, particulate matter, $\mathrm{O}_{3}$ and road traffic) were assigned to each participant's residential address.

Annual air pollution levels of $\mathrm{NO}_{2}$ and particulate matter were derived from ESCAPE standardised models (www.escapeproject.eu). Briefly, the ESCAPE monitoring campaigns took place between 2009 and 2010, including 40 measurement sites for $\mathrm{NO}_{2}$ and $\mathrm{NO}_{x}$ in Paris, Lyon, Grenoble and Marseille, and 20 particulate matter measurement sites in Paris and Grenoble. Land-use regression (LUR) models were developed and two indicators of road traffic were also calculated. Traffic intensity on nearest road was defined as the number of motor vehicles circulating per day on the nearest road to the participant's home and was expressed in vehicles per day. Total traffic load was defined as the traffic load on all major roads based around a buffer of $100 \mathrm{~m}$ from the participant's home and was expressed by traffic intensity multiplied by road length. Back-extrapolation was used to transfer the recent or current LUR models to earlier years. In our study, the estimation of outdoor air pollution by ESCAPE took place after EGEA2, and accordingly we also analysed the back-extrapolated pollution estimates in order to obtain a better temporality between outdoor air pollution with current asthma and EBC collection. Back-extrapolated pollution data were available for $\mathrm{NO}_{2}$ and $\mathrm{NO}_{x}$ in all cities, and for PM10 in Paris.

In order to supplement the ESCAPE data set, we used $\mathrm{O}_{3}$ and $\mathrm{O}_{3 \text {-summer }}$ exposures from the IFEN (see supplementary material for more details). The $\mathrm{O}_{3}$ estimate was the yearly mean ozone level in 2004 for each participant at the residential address and derived from a geo-statistical model as described previously [17]. The $\mathrm{O}_{3 \text {-summer }}$ exposure was assessed from the monthly means from April to September.

\section{Measurement of exhaled 8-iso}

EBC was collected at EGEA2 between 2003 and 2006 with an RTube (Respiratory Research, Charlottesville, VA, USA) according to a standardised method as described previously [18]. Samples were immediately stored at $-80^{\circ} \mathrm{C}$. Exhaled 8-iso concentration was measured 5.3-9.4 years after EBC collection, with a specific 8-iso enzyme immunoassay kit (Cayman Chemical, Ann Arbor, MI, USA) 
according to the manufacturer's protocol. Approximately $30 \%$ of the exhaled 8 -iso concentration measurements were below the limit of detection (see supplementary material for more details).

\section{Statistical analyses}

The level of outdoor air pollution was described by city. Due to its skewed distribution, the exhaled 8-iso concentration was $\log _{10}$-transformed.

Associations between outdoor air pollution and current asthma, and associations between exhaled 8-iso concentration and current asthma, were studied with logistic models. In order to study the association between outdoor air pollution and exhaled 8-iso concentration independently of asthma, linear regression models were first performed among participants without asthma and sensitivity analyses were conducted by: 1) using back-extrapolated pollution estimates, 2) studying the associations by city and 3) using bipollutant models (PM2.5 and $\mathrm{O}_{3}$ or $\mathrm{O}_{3 \text {-summer }}$ ). Analyses with back-extrapolated pollution estimates were performed to obtain a better temporality between pollution and EBC collection. We also studied the associations between outdoor air pollution and exhaled 8 -iso concentration in all participants and among participants with current asthma.

All estimates were adjusted for age, sex and smoking status. Further adjustments were conducted for body mass index (BMI), socioprofessional category and use of cleaning products, which is an indicator of exposure to indoor pollution. In order to study only the road traffic effect, estimates of associations between road traffic and current asthma or exhaled 8-iso concentration were also adjusted for background $\mathrm{NO}_{2}$. As the aim was to study the effect of long-term exposure to outdoor air pollution, we performed sensitivity analyses by excluding participants who lived at the same address for $<1$ year $(n=46)$.

In order to take into account the city effect on outdoor air pollution levels, we performed meta-analyses including city-specific analyses from the Harvard School of Public Health's macro program \%metaanal (www.hsph.harvard.edu/donna-spiegelman/software/metaanal) and pooled analyses with random effect on city.

The above models took into account random effects on familial dependence. All the results are expressed for an increase of $1 \mathrm{pg} \cdot \mathrm{mL}^{-1}$ of exhaled 8-iso concentration, $20 \mu \mathrm{g} \cdot \mathrm{m}^{-3}$ of $\mathrm{NO}_{x}, 10 \mu \mathrm{g} \cdot \mathrm{m}^{-3}$ of $\mathrm{NO}_{2}, \mathrm{PM}_{10}$,

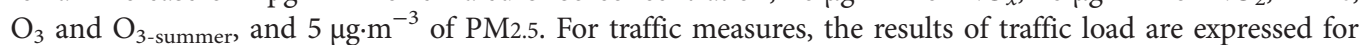
4 million vehicles $\times \mathrm{m}$ per day on major roads within a $100 \mathrm{~m}$ buffer and the results of traffic intensity are expressed for an increase of 5000 vehicles per day on major roads. Statistical analyses were performed using SAS version 9.4 (SAS Institute, Cary, NC, USA).

\section{Results}

The mean age of the 608 adults was 43 years, $47 \%$ were males, $39 \%$ had current asthma, $21 \%$ were current smokers and $37 \%$ were overweight $\left(B M I \geqslant 25 \mathrm{~kg} \cdot \mathrm{m}^{-2}\right.$ ) (table 1). Participants with current asthma were younger, more often men, current smokers and unemployed (table 1). Participants with current asthma had also a lower forced expiratory volume in $1 \mathrm{~s}(\mathrm{FEV} 1)$, higher airway hyperresponsiveness, higher allergic sensitisation, higher IgE level and higher exhaled 8-iso concentration than those without asthma.

The characteristics of participants were heterogeneous across cities (see supplementary material for more details).

The pollutant and traffic levels were the highest in Paris, except for the PM10 level (supplementary figures E1 and E2). The PM10 and PM2.5 levels were above the values recommended by the World Health

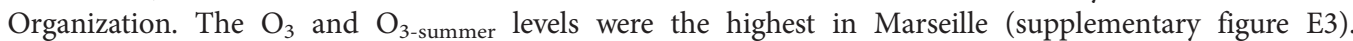
Positive and significant correlations were found between $\mathrm{NO}_{2}, \mathrm{NO}_{x}, \mathrm{PM} 10$ and $\mathrm{PM} 2.5(0.47 \leqslant \mathrm{r} \leqslant 0.95$; all $\mathrm{p}<0.002)$, whereas $\mathrm{O}_{3}$ and $\mathrm{O}_{3 \text {-summer }}$ levels were negatively correlated with all pollutants $(-0.50 \leqslant \mathrm{r} \leqslant-0.15$; all $\mathrm{p}<0.002$ ) (data not shown). The $\mathrm{NO}_{2}$ level was significantly higher in managers and technicians, and

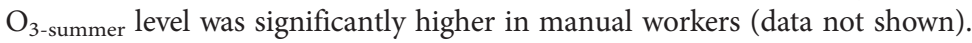

The geometric mean (interquartile range) exhaled 8-iso concentration was $3.16(1.41-7.69) \mathrm{pg} \cdot \mathrm{mL}^{-1}$ in all participants and 3.97 (1.85-9.10) $\mathrm{pg} \cdot \mathrm{mL}^{-1}$ among those with current asthma (table 1), and was seven times higher in Paris than in other cities, was higher in females and decreased with age (supplementary tables E2 and E3). No significant association was found between exhaled 8-iso concentration and smoking expressed as current smoker, quantity of tobacco or number of pack-years (all $\mathrm{p}>0.80$; data not shown). No interplate variability was observed (data not shown), and no association was found between storage time and exhaled 8-iso concentration (regression coefficient $0.02 ; \mathrm{p}=0.39$ ).

\section{Associations between outdoor air pollution and current asthma}

Associations between outdoor air pollution and current asthma were not significantly heterogeneous between cities (Q-test; $\mathrm{p}>0.08$ ). In pooled analyses, the risk of current asthma increased significantly with traffic intensity (adjusted (a)OR 1.09, 95\% CI 1.00-1.18) and with $\mathrm{O}_{3}$ exposure (aOR 2.04, 95\% CI 1.27-3.29) 
TABLE 1 Characteristics of adult participants according to asthma status

\begin{tabular}{|c|c|c|c|c|}
\hline & All participants & $\begin{array}{c}\text { Participants } \\
\text { without asthma }\end{array}$ & $\begin{array}{l}\text { Participants with } \\
\text { current asthma }\end{array}$ & p-value \\
\hline Subjects & 608 & 368 & 240 & \\
\hline Age years & $42.5 \pm 17.2$ & $45.5 \pm 26.3$ & $37.9 \pm 17.5$ & $<0.0001^{\uparrow}$ \\
\hline Male & $288(47.4)$ & $160(43.5)$ & $128(53.3)$ & $0.02^{\pi}$ \\
\hline Smoking status & & & & $0.02^{q 1}$ \\
\hline Never-smoker & 312 (51.3) & $189(51.4)$ & $123(51.3)$ & \\
\hline Ex-smoker & $168(27.6)$ & $113(30.7)$ & 55 (22.9) & \\
\hline Current smoker & $128(21.1)$ & $66(17.9)$ & 62 (25.8) & \\
\hline $\mathrm{BMI} \mathbf{k g} \cdot \mathrm{m}^{-2}$ & & & & 0.62 \\
\hline$<20$ & 70 (11.5) & 38 (10.3) & 32 (13.3) & \\
\hline $20-25$ & $316(52.0)$ & $193(52.4)$ & $123(51.3)$ & \\
\hline $25-30$ & $165(27.1)$ & 104 (28.3) & $61(25.4)$ & \\
\hline$\geqslant 30$ & $57(9.4)$ & $33(9.0)$ & $24(10.0)$ & \\
\hline Socioprofessional category & $n=605$ & $n=366$ & $n=239$ & $0.001^{\pi}$ \\
\hline Unemployed & $72(11.9)$ & $29(7.9)$ & 43 (18.0) & \\
\hline Manager & $212(35.0)$ & 138 (37.7) & $74(31.0)$ & \\
\hline Technician & $248(41.0)$ & 149 (40.7) & $99(41.4)$ & \\
\hline Manual worker & $73(12.1)$ & $50(13.7)$ & $23(9.6)$ & \\
\hline $\begin{array}{l}\text { Years at the same } \\
\text { residential address } \mathbf{n}\end{array}$ & $\begin{array}{c}12.4 \pm 10.7(0-48) \\
(n=607)\end{array}$ & $13.0 \pm 10.9(0-48)$ & $\begin{array}{c}11.4 \pm 10.4(0-46) \\
(n=239)\end{array}$ & 0.07 \\
\hline Current asthma & 240 (39.5) & & & \\
\hline Duration of asthma years & & & $\begin{array}{c}15.9 \pm 11.6(0-59.6) \\
(n=229)\end{array}$ & \\
\hline Age of asthma onset years & & & $n=228$ & \\
\hline$\leqslant 4$ & & & $80(35.1)$ & \\
\hline $5-16$ & & & 79 (34.7) & \\
\hline$>16$ & & & 69 (30.3) & \\
\hline FEV $1 \%$ pred & $103 \pm 18.9$ & $108 \pm 17.3$ & $95.2 \pm 18.5$ & $<0.0001^{\pi}$ \\
\hline Allergic sensitisation ${ }^{\#}$ & $\begin{array}{c}327(54.3) \\
(n=602)\end{array}$ & $\begin{array}{c}137(37.7) \\
(n=363)\end{array}$ & $\begin{array}{c}190(79.5) \\
(n=239)\end{array}$ & $<0.0001^{9}$ \\
\hline $\begin{array}{l}\text { Exhaled } 8 \text {-iso } \\
\text { concentration } \mathrm{pg} \cdot \mathrm{mL}^{-1}\end{array}$ & $3.16(1.41-7.69)$ & $2.69(1.14-6.79)$ & $3.97(1.85-9.10)$ & $0.004^{\natural}$ \\
\hline $\begin{array}{l}\text { Exhaled } 8 \text {-iso } \\
\text { concentration } \geqslant \text { LOD }\end{array}$ & $431(70.9)$ & $253(68.8)$ & $178(74.2)$ & 0.15 \\
\hline
\end{tabular}

Data are presented as $n$, mean $\pm \mathrm{SD}, \mathrm{n}(\%)$, mean $\pm \mathrm{SD}$ (minimum-maximum) or geometric mean (interquartile range), unless otherwise stated. $\mathrm{BMI}$ : body mass index; $\mathrm{FEV}_{1}$ : forced expiratory volume in $1 \mathrm{~s} ; 8$-iso: 8-isoprostane; LOD: limit of detection. " : defined by at least one weal $\geqslant 3 \mathrm{~mm}$ to 12 tested allergens (see supplementary material); ${ }^{\text {ๆ: }} \mathrm{p} \leqslant 0.05$.

(table 2) whatever the adjustment. The results were similar after excluding participants who lived at the same address for $<1$ year. Back-extrapolated exposure estimates gave similar results (supplementary table E4).

\section{Associations between exhaled 8-iso concentration and current asthma}

A positive and significant association was found between exhaled 8-iso concentration expressed as a continuous variable and current asthma (aOR 1.50, 95\% CI 1.06-2.12) (figure 2). No significant association was found when exhaled 8-iso concentration was expressed as below the limit of detection, or above or equal to the limit of detection. Overall, the risk of current asthma increased significantly with exhaled 8-iso concentration expressed as below the limit of detection, above or equal to the limit of detection and less than or equal to the median, or above or equal to the limit of detection and greater than the median $\left(\mathrm{p}_{\text {trend }}=0.05\right)$.

Exhaled 8-iso concentration was unrelated to duration of asthma (years) or age of asthma onset expressed continuously (years) or in classes (all $\mathrm{p}>0.40$ ). Furthermore, no significant association was found between exhaled 8-iso concentration with $\mathrm{FEV}_{1} \%$ predicted continuously or in classes (all $\mathrm{p}>0.60$ ) or allergic sensitisation $(\mathrm{p}=0.12)$ (data not shown).

\section{Associations between outdoor air pollution and exhaled 8-iso concentration among participants without asthma}

Associations between outdoor air pollution and exhaled 8-iso concentration were not heterogeneous between cities (Q-test; $\mathrm{p}>0.20$ ). In pooled analyses, exhaled 8-iso concentration increased significantly with 
TABLE 2 Associations between outdoor air pollution and current asthma

\begin{tabular}{|c|c|c|c|c|c|c|c|c|}
\hline & $\mathrm{NO}_{2}$ & $\mathrm{NO}_{x}$ & $\mathrm{PM}_{10}$ & PM2.5 & $\begin{array}{l}\text { Total traffic load } \\
\text { on major roads } \\
\text { in a } 100 \mathrm{~m} \text { buffer } \\
\text { around the } \\
\text { home }\end{array}$ & $\begin{array}{l}\text { Traffic intensity } \\
\text { on the road } \\
\text { nearest to the } \\
\text { participant's } \\
\text { home }^{\#}\end{array}$ & $\mathrm{O}_{3}$ & $\mathbf{O}_{3 \text {-summer }}$ \\
\hline \multicolumn{9}{|l|}{ Model 1} \\
\hline $\mathrm{n}$ & 608 & 608 & 437 & 437 & 605 & 605 & 603 & 603 \\
\hline \multicolumn{9}{|l|}{ Model 2} \\
\hline $\mathrm{n}$ & 608 & 608 & 437 & 437 & 608 & 608 & 603 & 603 \\
\hline $\mathrm{aOR}$ & 0.99 & 1.04 & 1.05 & 0.82 & 1.15 & $1.09^{\pi}$ & $1.93^{\natural}$ & 1.10 \\
\hline (95\% CI) & $(0.86-1.14)$ & (0.91-1.18) & $(0.62-1.79)$ & $(0.49-1.36)$ & (0.95-1.38) & $(1.00-1.19)$ & (1.21-3.09) & $(0.67-1.81)$ \\
\hline \multicolumn{9}{|l|}{ Model 3} \\
\hline$n$ & 605 & 605 & 436 & 436 & 605 & 605 & 600 & 600 \\
\hline $\mathrm{aOR}$ & 0.98 & 1.03 & 1.03 & 0.82 & 1.14 & $1.09^{\text {? }}$ & $2.04^{\pi}$ & 1.24 \\
\hline (95\% CI) & $(0.85-1.14)$ & (0.90-1.17) & (0.59-1.80) & (0.49-1.39) & (0.94-1.37) & $(1.00-1.18)$ & (1.27-3.29) & $(0.71-2.18)$ \\
\hline \multicolumn{9}{|l|}{ Model 5} \\
\hline $\mathrm{n}$ & 557 & 557 & 400 & 400 & 557 & 557 & 553 & 553 \\
\hline $\mathrm{aOR}$ & 0.99 & 1.04 & 1.03 & 0.89 & 1.18 & $1.10^{\text {ๆ }}$ & $1.67^{\Uparrow}$ & 1.06 \\
\hline (95\% CI) & $(0.86-1.16)$ & (0.91-1.19) & (0.57-1.85) & (0.52-1.53) & $(0.97-1.45)$ & $(1.00-1.19)$ & $(1.06-2.63)$ & $(0.77-1.45)$ \\
\hline \multicolumn{9}{|c|}{ 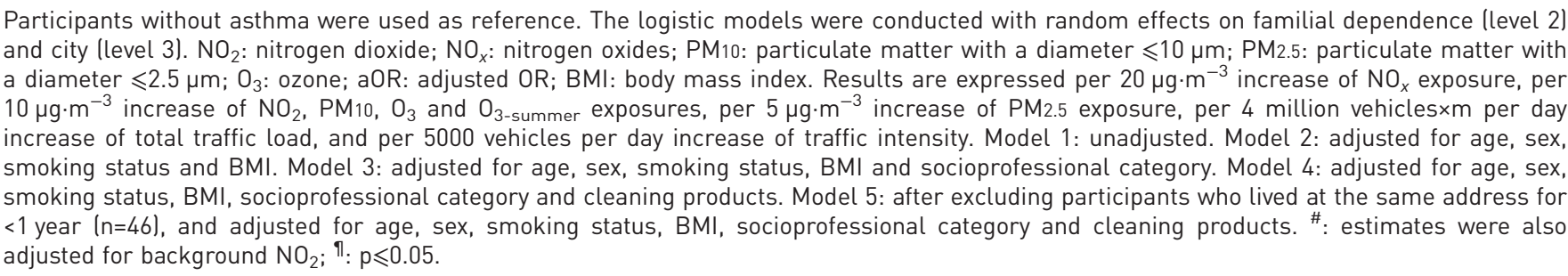 } \\
\hline
\end{tabular}

PM2.5 exposure (adjusted (a) $\beta$ 0.23, 95\% CI 0.005-0.46), and decreased with $\mathrm{O}_{3}$ and $\mathrm{O}_{3 \text {-summer }}$ exposures (a $\beta-0.20,95 \%$ CI $-0.39--0.01$ and $a \beta-0.52,95 \%$ CI $-0.77--0.26$, respectively) whatever the adjustment (table 3 ). The results were similar after excluding participants who lived at the same address

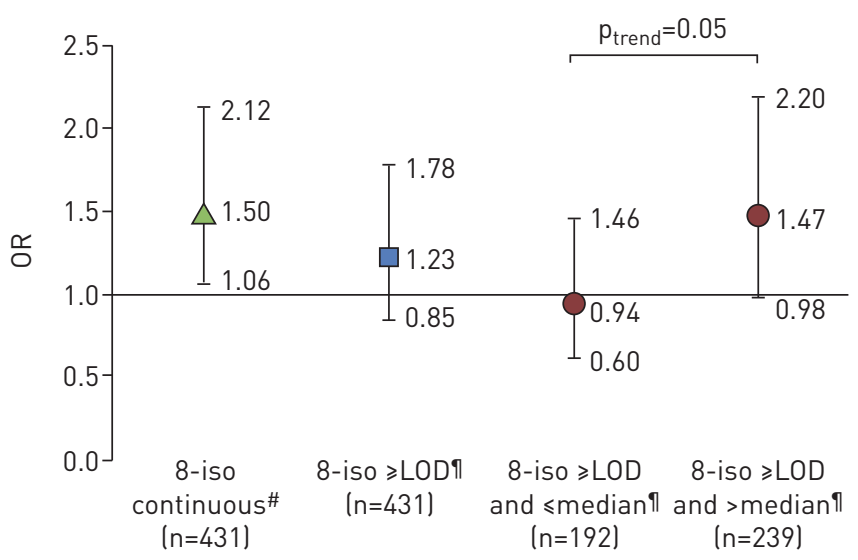

FIGURE 2 Associations between exhaled 8-isoprostane (8-iso) concentration and current asthma. LOD: limit of detection. The logistic models were conducted with random effects on familial dependence. Estimates were adjusted for age, sex, smoking status and body mass index. 8 -iso concentration was $\log _{10}$-transformed. Data are presented as odds ratios and $95 \%$ confidence intervals with participants without asthma as reference. \#: result is expressed of an increase for 1 unit of the concentration in 8-iso; ": 8-iso <LOD was used as reference category. 
TABLE 3 Associations between outdoor air pollution and exhaled 8-isoprostane (8-iso) concentration among participants without asthma

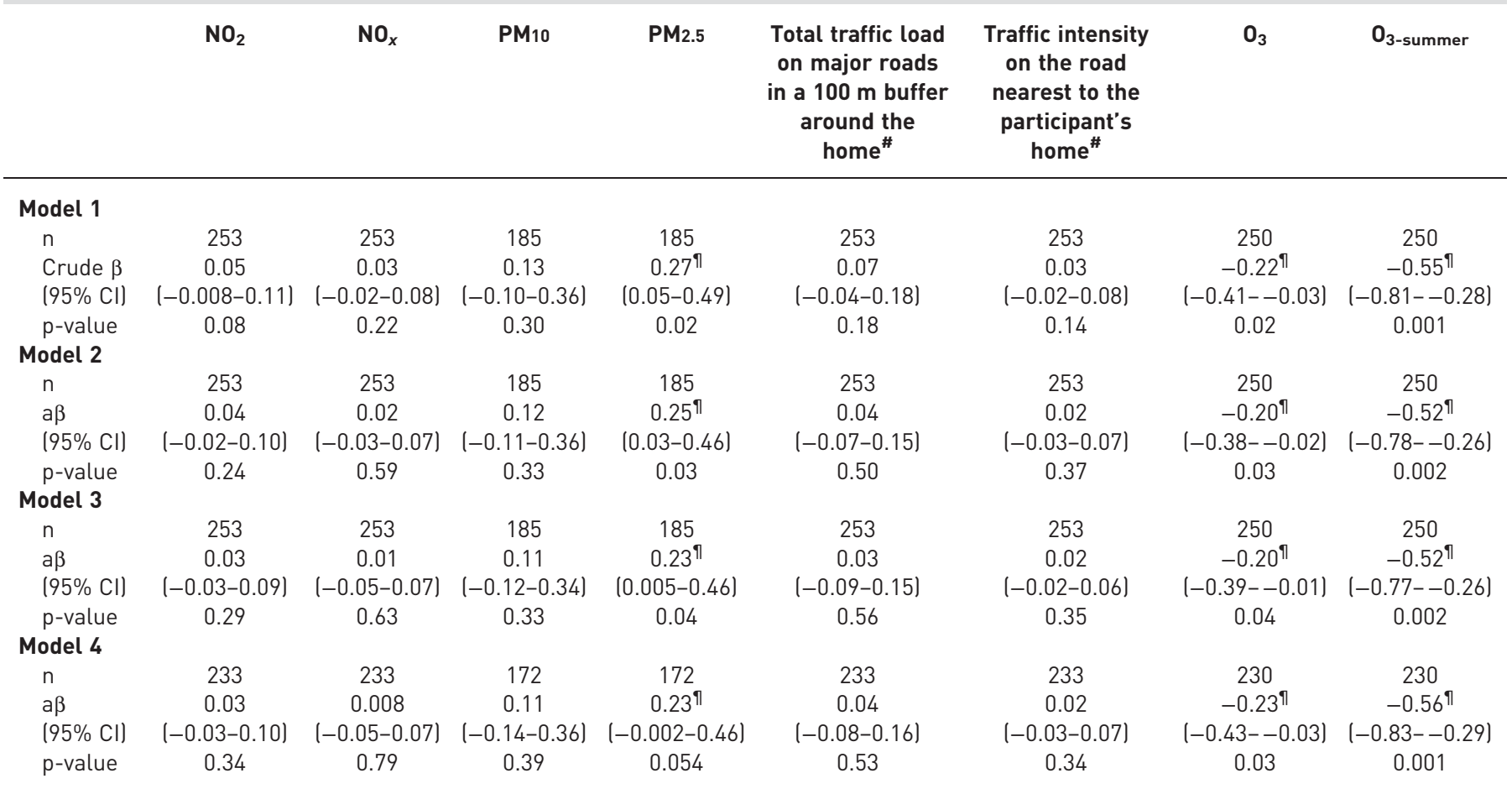

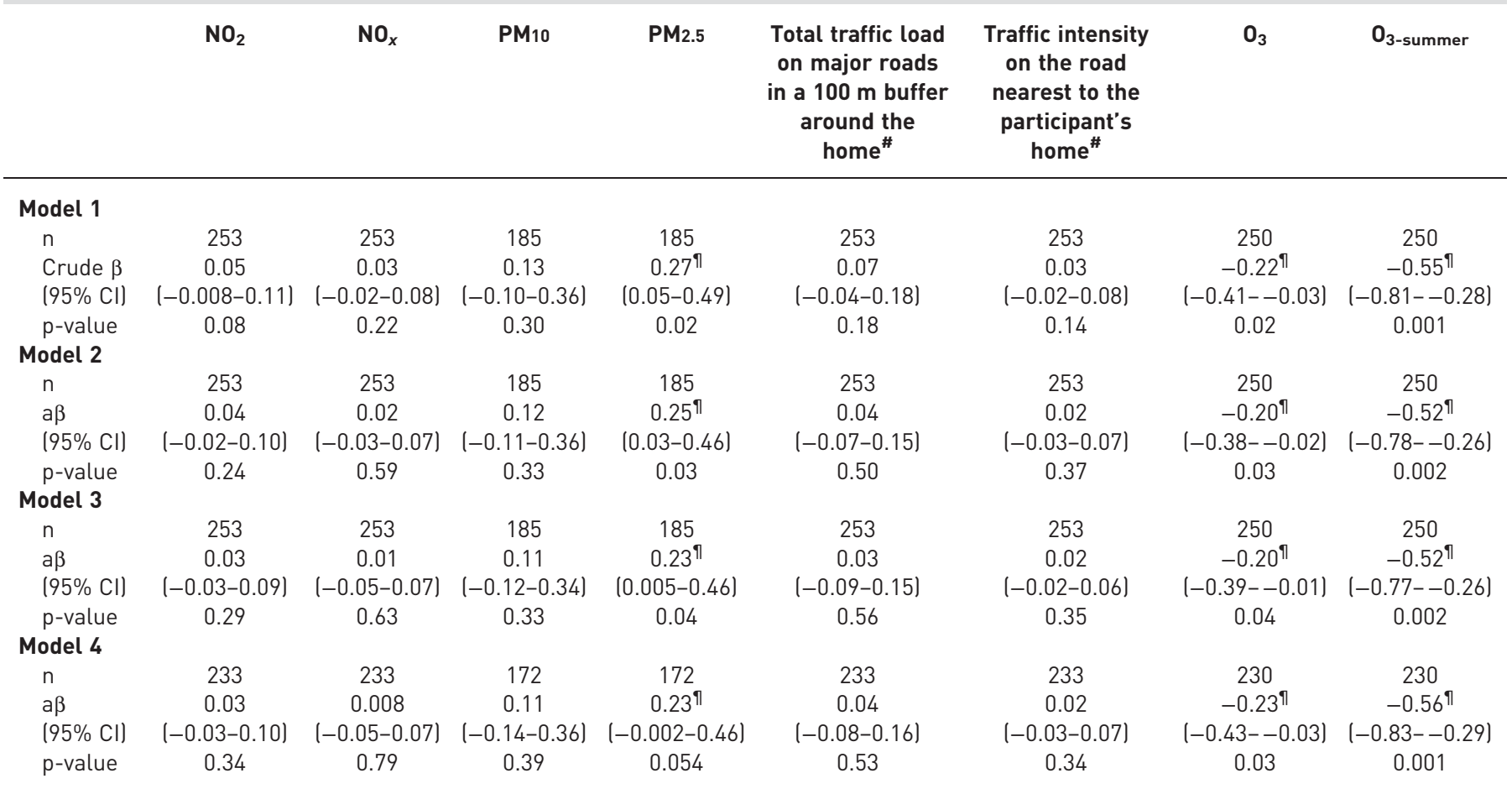

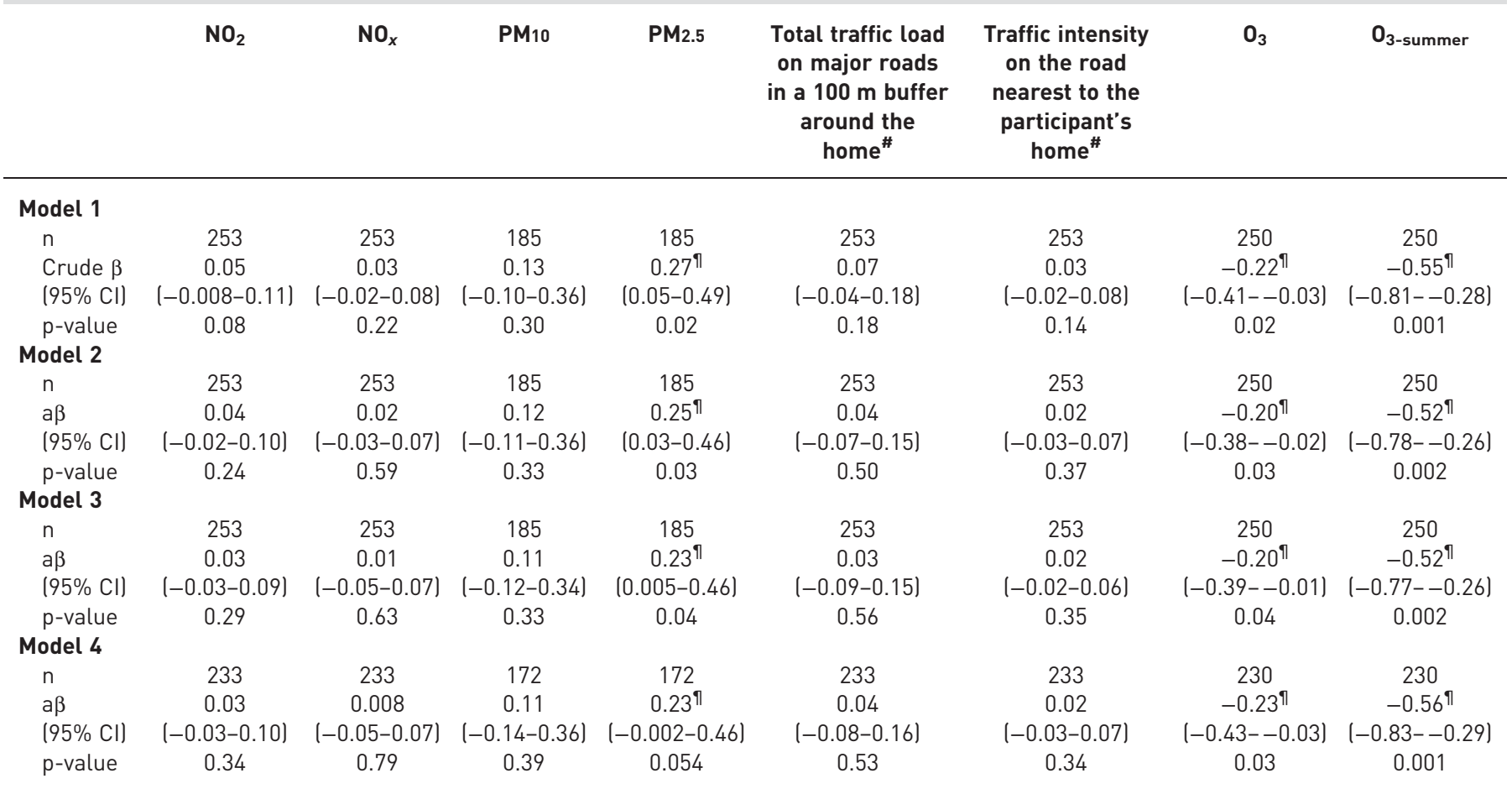

$\mathbf{O}_{3} \quad \mathbf{O}_{3 \text {-summer }}$

The linear regression models were conducted with random effects on familial dependence (level 2) and city (level 3). 8-iso concentration was $\log _{10}$-transformed. $\mathrm{NO}_{2}$ : nitrogen dioxide; $\mathrm{NO}_{x}$ : nitrogen oxides; $\mathrm{PM10}$ : particulate matter with a diameter $\leqslant 10 \mu \mathrm{m} ; \mathrm{PM} 2.5$ : particulate matter with a diameter $\leqslant 2.5 \mu \mathrm{m} ; \mathrm{O}_{3}$ : ozone; a 3 : adjusted $\beta$. Results are expressed per $20 \mu \mathrm{g} \cdot \mathrm{m}^{-3}$ increase of $\mathrm{NO}_{x}$ exposure, per $10 \mu \mathrm{g} \cdot \mathrm{m}^{-3}$ increase of $\mathrm{NO}_{2}, \mathrm{PM} 10, \mathrm{O}_{3}$ and $\mathrm{O}_{3}$-summer exposures, per $5 \mu \mathrm{g} \cdot \mathrm{m}^{-3}$ increase of PM2.5 exposure, per 4 million vehicles $\times \mathrm{m}$ per day increase of total traffic load, and per 5000 vehicles per day increase of traffic intensity. Model 1: unadjusted. Model 2: adjusted for age, sex and smoking status. Model 3: adjusted for age, sex, smoking status and cleaning products. Model 4: after excluding participants who lived at the same address for $<1$ year $(n=46)$, and adjusted for age, sex, smoking status, body mass index, socioprofessional category and cleaning products. ${ }^{\#}$ : estimates were also adjusted for background $\mathrm{NO}_{2} ;{ }^{\text {१: }} \mathrm{p} \leqslant 0.05$.

for $<1$ year. Analyses performed with back-extrapolated data also gave similar results (supplementary table E5). Furthermore, exhaled 8-iso concentration decreased significantly with $\mathrm{O}_{3}$ and $\mathrm{O}_{3 \text {-summer }}$ exposures in Paris $(\mathrm{a} \beta-0.22,95 \% \mathrm{CI}-0.42--0.02)$ and $\mathrm{a} \beta-0.53,95 \% \mathrm{CI}-0.90--0.16$, respectively) (supplementary table E6). After excluding participants from Paris $(n=111)$, no significant associations were observed between $\mathrm{O}_{3}$ and $\mathrm{O}_{3 \text {-summer }}$ and exhaled 8-iso concentration (supplementary table E7). In models adjusted

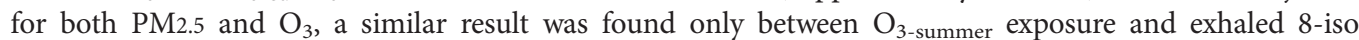
concentration ( $\mathrm{a} \beta-0.59,95 \% \mathrm{CI}-0.71--0.47)$ (supplementary table E8). In models adjusted for both $\mathrm{NO}_{2}$ and $\mathrm{O}_{3}$, the negative associations between $\mathrm{O}_{3}$ and $\mathrm{O}_{3 \text {-summer }}$ and exhaled 8-iso concentration remained statistically significant (data not shown). In all participants, only $\mathrm{O}_{3 \text {-summer }}$ exposure was negatively and significantly associated with exhaled 8 -iso concentration (a $\beta-0.33,95 \% \mathrm{CI}-0.55--0.11$ ) (data not shown). No association was found between outdoor air pollution and exhaled 8-iso concentration in participants with current asthma (data not shown).

\section{Discussion}

For the first time in adults, we found associations between long-term exposures to outdoor air pollution estimated at the individual level, exhaled 8-iso concentration and current asthma. Traffic intensity and $\mathrm{O}_{3}$ exposure significantly increased the risk of current asthma. Exhaled 8-iso concentration was positively and significantly associated with current asthma. Among participants without asthma, exhaled 8-iso concentration significantly increased with PM2.5 exposure, and decreased with $\mathrm{O}_{3}$ and $\mathrm{O}_{3 \text {-summer }}$ exposures.

Participants with asthma included in the present analyses were mostly recruited in chest clinics as asthma cases, with a careful procedure set up to include true asthmatic subjects using standardised and validated questionnaires. Others were recruited as first-degree relatives of asthmatic cases based on answers to questions on asthma diagnosis. This led to a group of asthmatic subjects with a wide range of disease 
expression. In our cross-sectional analyses, cause and consequence cannot be disentangled. It was not possible to study the associations between outdoor air pollution and exhaled 8-iso concentration with the incidence of asthma because only 30 new cases of asthma were reported at EGEA2. However, there is clearly a need for further research to confirm the associations and to clarify its causal underpinnings. Regarding exposure assessment, LUR models are well adapted to take into account the spatial variation of $\mathrm{NO}_{2}, \mathrm{PM}_{2.5}$ [19] and $\mathrm{NO}_{x}$ [20], and ESCAPE resolution is accurate to estimate the exposure to markers of road traffic, which have a spatial heterogeneity. In addition, IFEN resolution is larger than ESCAPE, but

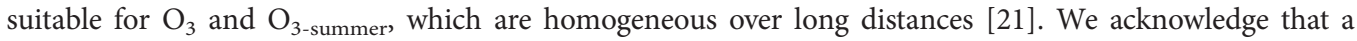
weakness of our study is the noncompliance of the temporality because outdoor air pollution was estimated by ESCAPE between 2009 and 2010, whereas the collection of EBC and phenotype "current asthma" took place at EGEA2 between 2003 and 2007. To obtain a better temporality in our analyses, we used the back-extrapolated pollution estimates, which were back-extrapolated at the participant's residential address at EGEA2, and found similar results. Both back-extrapolated and non-back-extrapolated estimates were highly and significantly correlated in our study (correlation coefficients $\geqslant 0.98 ; \mathrm{p}<0.001$ ), as previously reported by BEELEN et al. [22] in the same ESCAPE project and for a longer period. Previously in the ESCAPE study, associations between $\mathrm{NO}_{2}$ back-extrapolated estimates and asthma incidence were similar to those with non-back-extrapolated estimates [23]. We aimed to study the impact of long-term exposure to outdoor air pollution and therefore conducted sensitivity analyses by excluding participants who lived at the same residential address for $<1$ year, which did not change our conclusions. We cannot exclude that some nondifferential misclassification of pollution exposure may have occurred because the time-activity patterns of participants were not available in our analyses, but in this case it would lead to bias towards the null. Furthermore, IFEN resolution can

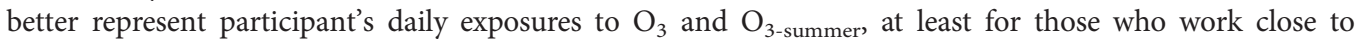
home. We could not take into account all indoor environmental factors; however, we found similar results after further adjustment for domestic exposure to cleaning products. Furthermore, adjustment for socioeconomic position potentially associated with pollutant exposures [24] and asthma also gave similar results. The EGEA study is a case-control and family study. Participants from the same family share a genetic background, and also socioeconomic and lifestyle factors, that could be associated with exposure to outdoor air pollution or asthma risk. We therefore took into account familial dependence through random effects in mixed models. Subgroup analyses suffer from a lack of power but, as best as possible, we used the most suitable statistical models. Finally, the enzyme immunoassay method has been preferred for dosing exhaled 8-iso concentration rather the gas chromatography-mass spectrometry method because the former is better adapted to analyse a larger number of samples, as in our study.

We found that traffic intensity and $\mathrm{O}_{3}$ exposure increased the risk of current asthma. Our results add evidence of the impact of long-term exposure to outdoor air pollution on asthma in adults. Our results are partly in accordance with those of a recent study showing that traffic exposure but not $\mathrm{NO}_{2}$ exposure, assessed by satellite-based LUR model at residential addresses, was positively associated with current asthma in 1367 adults [25]. We also found a positive association between $\mathrm{O}_{3}$ exposure and current asthma. To the best of our knowledge, the literature assessing the effects of outdoor air pollution on asthma has been focused mainly on other asthma phenotypes such as asthma onset, asthma severity or asthma control. A study conducted in California in the USA reported that long-term exposure to $\mathrm{O}_{3}$ was associated with development of asthma in adult males [26]. Previously in the EGEA study, long-term exposure to $\mathrm{O}_{3}$ estimated by IFEN was associated with asthma severity [17] and with uncontrolled asthma [27]. Recently, a cohort showed that asthmatic adults exposed to $\mathrm{O}_{3}$ had a greater risk of developing asthma-chronic obstructive pulmonary disease overlap syndrome [28]. Interestingly, various asthma phenotypes were studied such as asthma onset, which reflects the initiation of the disease, and severity and control of asthma, which are linked to manifestations of the disease. Asthma reflects both ever-asthma and current asthma, and the participants with ever-asthma did not necessarily have current asthma. In the EGEA study, the phenotype "current asthma" was defined by the report of respiratory symptoms or asthma attacks, or use of inhaled and/or oral medicines because of breathing problems in the past 12 months. To study the associations between long-term exposure to outdoor air pollution, biological markers and asthma, the phenotype "current asthma" was more relevant than the phenotype "ever-asthma" because it reflects the recent activity of the disease. Overall, all these findings add evidence of associations between outdoor air pollution and asthma in adults, whatever the studied phenotypes.

This study adds new insights into a potential role of oxidative stress in the associations between long-term exposure to outdoor air pollution and asthma in adults. We reported a significant association between exhaled 8-iso concentration and current asthma after adjustment for age, sex, smoking status and BMI. We investigated whether other asthma characteristics could explain this association, but we did not find any significant association between exhaled 8-iso concentration and duration of asthma, age of asthma onset, lung function or allergic sensitisation. Our results add new evidence to the previous associations reported 
in the literature on asthma severity and asthma control [12]. We found for the first time that exhaled 8-iso concentration was positively associated with $\mathrm{PM} 2.5$ exposure in participants without asthma. Unfortunately, we did not have back-extrapolated data for PM2.5. In France, the PM2.5 level has shown an overall decrease between 2002 and 2012, and the association between PM2.5 exposure and exhaled 8-iso concentration may be underestimated [29]. The literature has been mainly focused on short-term exposure to outdoor air pollution and on other biological compartments. In fact, short-term exposure to PM2.5 was previously found to be positively associated with EBC 8-iso concentration among healthy adolescents [30] and with 8-iso concentration in urine among adults [31]. We also found counterintuitive negative associations between $\mathrm{O}_{3}$ and $\mathrm{O}_{3 \text {-summer }}$ exposures and exhaled 8-iso concentration. Our results are not in accordance with those of a previous study showing that $\mathrm{O}_{3}$ exposure assigned to residential location was associated with higher plasma 8-iso concentration in 120 healthy students [32]. The inconsistency with our findings may be partially attributed to differences in the study design, biological compartment and spatial resolution, which was less accurate than in our study. We showed that $\mathrm{O}_{3}$ exposure and exhaled 8 -iso concentration increased the risk of current asthma, and we did not expect negative associations between $\mathrm{O}_{3}$ and $\mathrm{O}_{3 \text {-summer }}$ exposures and exhaled 8-iso concentration. We investigated more thoroughly why these associations were negative. The analyses conducted by city showed that Paris heavily weighted the negative associations between $\mathrm{O}_{3}$ and $\mathrm{O}_{3 \text {-summer }}$ exposures and exhaled 8-iso concentration. Previously, a study has also reported a negative association between short-term exposure to $\mathrm{O}_{3}$ and exhaled 8-iso in adolescents in New York in the USA [33]. Another explanation is that $\mathrm{O}_{3}$ is a secondary pollutant mainly produced through complex chemical reactions from $\mathrm{NO}_{2}$. In our study, $\mathrm{O}_{3}$ and $\mathrm{NO}_{2}$ levels were highly and negatively correlated, and $\mathrm{NO}_{2}$ exposure was also positively associated with exhaled 8-iso concentration, but not significantly. One likely hypothesis is that the positive association between $\mathrm{NO}_{2}$ and exhaled 8-iso partly explained the negative associations observed for $\mathrm{O}_{3}$ and $\mathrm{O}_{3}$-summer. Overall, the specific effects of pollutants are hard to disentangle even in bipollutant models given the strong correlations between pollutants. It is interesting to note that participants from Paris had an exhaled 8-iso concentration seven times higher, and were exposed to higher levels of road traffic, $\mathrm{NO}_{2}$ and particulate matter, and to

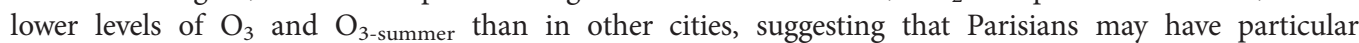
characteristics that could partly explain the negative associations between $\mathrm{O}_{3}$ and exhaled 8-iso concentration. $\mathrm{O}_{3}$ and $\mathrm{O}_{3 \text {-summer }}$ were negatively correlated with $\mathrm{PM} 2.5$, but the negative association between $\mathrm{O}_{3 \text {-summer }}$ exposure and exhaled 8-iso concentration remained significant in a bipollutant model. Previously in EGEA adults, $\mathrm{O}_{3}$ assessed by IFEN was also found to be negatively associated with the EBC total nitrites/nitrates level, a biological marker of nitrosative stress [21]. In the literature, complex interplays between nitrosative and oxidative stress pathways have been reported [34], including a reciprocal regulation. An alternative explanation is that our results were likely due to other factors that are not included in the present analyses. In all participants, only a negative and significant association between $\mathrm{O}_{3 \text {-summer }}$ exposure and exhaled 8-iso concentration was found, and no association was found in participants with current asthma. In a directed acyclic graph, the covariate "current asthma" may be a collider, which makes the interpretation of our results even more difficult in a context of cross-sectional analyses [35].

Several biological mechanisms by which outdoor air pollution may be associated with asthma have been suggested in previous reviews [36, 37]. Outdoor air pollution exposure may increase oxidative stress in airways through the production of reactive oxygen species and local inflammation [9]. The particulate matter can act as supports for allergens and their small size gives them a large surface related to oxidative potential [38]. To disentangle the complexity of the associations between asthma and oxidative stress, and 8 -iso in particular, there is a need for longitudinal epidemiological studies. Overall, our results add new insights into a potential role of oxidative stress in the association between long-term exposure to outdoor air pollution and asthma in adults. To better understand the underlying biological pathways between outdoor air pollution and asthma, future epidemiological studies should use individual portable sensors in order to improve the pollution assessment, study the different windows of exposure and try to collect multiple exposures in order to identify exposure profiles through clustering methods.

In conclusion, we found that traffic intensity, $\mathrm{O}_{3}$ exposure and exhaled 8-iso concentration increased the risk of current asthma, and that among participants without asthma exhaled 8-iso concentration increased with PM2.5 exposure, and decreased with $\mathrm{O}_{3}$ and $\mathrm{O}_{3 \text {-summer }}$ exposures. Exhaled 8-iso seems to be an interesting oxidative stress-related biomarker adapted to epidemiological studies. Overall, our study adds new insights into the associations between long-term exposure to outdoor air pollution and asthma in adults, and suggests that oxidative stress may partly explain such associations. Longitudinal studies with larger samples are now needed to confirm such results.

Acknowledgements: The authors thank all those who participated in the setting of the study and in the various aspects of the examinations involved: interviewers, technicians for lung function testing and skin prick tests, blood sampling, 
IgE determinations, coders, those involved in quality control, data and sample management, and all those who supervised the study in all centres. The authors are grateful to the three CIC-INSERM centres of Necker, Grenoble and Marseille who supported the study and in which participants were examined. They are also grateful to the biobanks in Lille (CIC-INSERM) and at Annemasse (Etablissement Français du Sang) where biological samples are stored. They are indebted to all the individuals who participated, without whom the study would not have been possible. The authors thank N. Jeannée (Géovariances, Avon, France) and all those from the French Institute for Environment (Orléans, France), particularly $\mathrm{M}$. Ba, for their work on the geospatial models.

The EGEA cooperative groupis as follows. Coordination: V. Siroux (epidemiology; Principal Investigator since 2013), F. Demenais (genetics), I. Pin (clinical aspects), R. Nadif (biology), F. Kauffmann (Principal Investigator 1992-2012). Respiratory epidemiology: INSERM ex-U700, Paris: M. Korobaeff (EGEA1), F. Neukirch (EGEA1); INSERM ex-U707, Paris: I. Annesi-Maesano (EGEA1 and 2); INSERM ex-U1018, Villejuif: F. Kauffmann, M.P. Oryszczyn (EGEA1 and 2); INSERM U1168, Villejuif: N. Le Moual, R. Nadif, R. Varraso; INSERM U1209 Grenoble: V. Siroux. Genetics: INSERM ex-U393, Paris: J. Feingold; INSERM U946, Paris: E. Bouzigon, F. Demenais, M.H. Dizier; CNG, Evry: I. Gut (now CNAG, Barcelona, Spain), M. Lathrop (now McGill University, Montreal, QC, Canada). Clinical centres: Grenoble: I. Pin, C. Pison; Lyon: D. Ecochard (EGEA1), F. Gormand, Y. Pacheco; Marseille: D. Charpin (EGEA1), D. Vervloet (EGEA1 and 2); Montpellier: J. Bousquet; Paris Cochin: A. Lockhart (EGEA1), R. Matran (now Lille); Paris Necker: E. Paty (EGEA1 and 2), P. Scheinmann (EGEA1 and 2); Paris Trousseau: A. Grimfeld (EGEA1 and 2), J. Just. Data and quality management: INSERM ex-U155 (EGEA1): J. Hochez; INSERM U1168: N. Le Moual; INSERM ex-U780: C. Ravault (EGEA1 and 2); INSERM ex-U794: N. Chateigner (EGEA1 and 2); Grenoble: J. Quentin (EGEA1 and 2).

Conflict of interest: V. Siroux reports personal fees (speaker honorarium) from Teva, AstraZeneca and Novartis, outside the submitted work.

Support statement: Research was funded in part by the National Hospital Program of Clinical Research (PHRC-national 2012, EvAdA), ANR-CES-2009, Region Nord Pas-de-Calais, Merck Sharp \& Dohme, the GA ${ }^{2}$ LEN (Global Allergy and Asthma European Network) project and the Fonds AGIR pour les Maladies Chroniques. ESCAPE (FP7/2007-2011, grant 211250). Anaïs Havet is financed by CHU de Lille.

\section{References}

1 Pascal M, De Crouy Chanel P, Wagner V, et al. The mortality impacts of fine particles in France. Sci Total Environ 2016; 571: 416-425.

2 Kelly FJ, Fussell JC. Air pollution and airway disease. Clin Exp Allergy 2011; 41: 1059-1071.

3 Mannucci PM, Harari S, Martinelli I, et al. Effects on health of air pollution: a narrative review. Intern Emerg Med 2015; 10: 657-662.

4 Goldizen FC, Sly PD, Knibbs LD. Respiratory effects of air pollution on children. Pediatr Pulmonol 2016; 51: 94-108.

5 Jacquemin B, Schikowski T, Carsin A, et al. The role of air pollution in adult-onset asthma: a review of the current evidence. Semin Respir Crit Care Med 2012; 33: 606-619.

6 Guarnieri M, Balmes JR. Outdoor air pollution and asthma. Lancet 2015; 383: 1581-1592.

7 Czerska M, Zieliński M, Gromadzińska J. Isoprostanes - a novel major group of oxidative stress markers. Int Occup Med Environ Health 2016; 29: 179-190.

8 Roberts LJ, Morrow JD. Measurement of $\mathrm{F}_{2}$-isoprostanes as an index of oxidative stress in vivo. Free Radic Bio Med 2000; 28: 505-513.

9 Kelly FJ. Oxidative stress: its role in air pollution and adverse health effects. Occup Environ Med 2003; 60: 612-616.

10 Wood L, Gibson PG, Garg ML. Biomarkers of lipid peroxidation, airway inflammation and asthma. Eur Respir J 2003; $21: 177-186$

11 Janssen LJ. The pulmonary biology of isoprostanes. Chem Phys Lipids 2004; 128: 101-116.

12 Aldakheel FM, Thomas PS, Bourke JE, et al. Relationships between adult asthma and oxidative stress markers and $\mathrm{pH}$ in exhaled breath condensate: a systematic review. Allergy 2016; 71: 741-757.

13 Kauffmann F, Dizier MH. EGEA (Epidemiological study on the Genetics and Environment of Asthma, bronchial hyperresponsiveness and atopy) - design issues. Clin Exp Allergy 1995; 25: Suppl. 2, 19-22.

14 Kauffmann F, Dizier M-H, Annesi-Maesano I, et al. EGEA (Epidemiological study on the Genetics and Environment of Asthma, bronchial hyperresponsiveness and atopy) - descriptive characteristics. Clin Exp Allergy 1999; 29: 17-21.

15 Nadif R, Bouzigon E, Le Moual N, et al. EGEA Collection: a biobank devoted to asthma and asthma-related phenotypes. Open J Bioresources 2017; 4: 5.

16 Siroux V, Boudier A, Bousquet J, et al. Phenotypic determinants of uncontrolled asthma. J Allergy Clin Immunol 2009; 124: 681-687.

17 Rage E, Siroux V, Künzli N, et al. Air pollution and asthma severity in adults. Occup Environ Med 2009; 66: $182-188$

18 Nadif R, Rava M, Decoster B, et al. Exhaled nitric oxide, nitrite/nitrate levels, allergy, rhinitis and asthma in the EGEA study. Eur Respir J 2014; 44: 351-360.

19 Wang M, Beelen R, Bellander T, et al. Performance of multi-city land use regression models for nitrogen dioxide and fine particles. Environ Health Perspect 2014; 122: 843-849.

20 Beelen R, Hoek G, Vienneau D, et al. Development of $\mathrm{NO}_{2}$ and $\mathrm{NO}_{x}$ land use regression models for estimating air pollution exposure in 36 study areas in Europe - the ESCAPE project. Atmos Environ 2013; 72: 10-23.

21 Rava M, Varraso R, Decoster B, et al. Plasma and exhaled breath condensate nitrite-nitrate level in relation to environmental exposures in adults in the EGEA study. Nitric Oxide 2012; 27: 169-175.

22 Beelen R, Hoek G, Fischer P, et al. Estimated long-term outdoor air pollution concentrations in a cohort study. Atmos Environ 2007; 41: 1343-1358.

23 Jacquemin B, Siroux V, Sanchez M, et al. Ambient air pollution and adult asthma incidence in six European cohorts (ESCAPE). Environ Health Perspect 2015; 123: 613-622. 
24 Temam S, Burte E, Adam M, et al. Socioeconomic position and outdoor nitrogen dioxide $\left(\mathrm{NO}_{2}\right)$ exposure in Western Europe: a multi-city analysis. Environ Int 2017; 101: 117-124.

25 Bowatte G, Lodge CJ, Knibbs LD, et al. Traffic-related air pollution exposure is associated with allergic sensitization, asthma, and poor lung function in middle age. J Allergy Clin Immunol 2016; 139: 1-9.

26 McDonnell WF, Abbey DE, Nishino N, et al. Long-term ambient ozone concentration and the incidence of asthma in nonsmoking adults: the AHSMOG study. Environ Res 1999; 80: 110-121.

27 Jacquemin B, Kauffmann F, Pin I, et al. Air pollution and asthma control in the Epidemiological study on the Genetics and Environment of Asthma. J Epidemiol Community Health 2012; 66: 796-802.

28 To T, Zhu J, Larsen K, et al. Progression from asthma to chronic obstructive pulmonary disease is air pollution a risk factor? Am J Respir Crit Care Med 2016; 194: 429-438.

29 Airparif. Évolution qualité de l'air à Paris entre 2002-2012. [Evolution of air quality in Paris between 2002-2012.] 2013. www.airparif.asso.fr/_pdf/publications/rapport-pdp-130703.pdf Date last accessed: March 1, 2018.

30 Hashemzadeh $\mathrm{B}$, Idani E, Goudarzi G, et al. Effects of $\mathrm{PM}_{25}$ and $\mathrm{NO}_{2}$ on the 8-isoprostane and lung function indices of FVC and $\mathrm{FEV}_{1}$ in students of Ahvaz city, Iran. Saudi J Biol Sci 2016; in press [https://doi.org/10.1016/j. sjbs.2016.11.008].

31 Li W, Wilker EH, Dorans KS, et al. Short-term exposure to air pollution and biomarkers of oxidative stress: the Framingham Heart Study. J Am Heart Assoc 2016; 5: e002742.

32 Chen C, Arjomandi M, Balmes J, et al. Effects of chronic and acute ozone exposure on lipid peroxidation and antioxidant capacity in healthy young adults. Environ Health Perspect 2007; 115: 1732-1737.

33 Patel MM, Chillrud SN, Deepti KC, et al. Traffic-related air pollutants and exhaled markers of airway inflammation and oxidative stress in New York City adolescents. Environ Res 2013; 121: 71-78.

34 Cuzzocrea S, Salvemini D. Molecular mechanisms involved in the reciprocal regulation of cyclooxygenase and nitric oxide synthase enzymes. Kidney Int 2007; 71: 290-297.

35 Suttorp MM, Siegerink B, Jager KJ, et al. Graphical presentation of confounding in directed acyclic graphs. Nephrol Dial Transplant 2015; 30: 1418-1423.

36 Gowers AM, Cullinan P, Ayres JG, et al. Does outdoor air pollution induce new cases of asthma? Biological plausibility and evidence; a review. Respirology 2012; 17: 887-898.

37 Bernstein JA, Alexis N, Barnes C, et al. Health effects of air pollution. J Allergy Clin Immunol 2004; 114 1116-1123.

38 Beck-Speier I, Dayal N, Karg E, et al. Oxidative stress and lipid mediators induced in alveolar macrophages by ultrafine particles. Free Radic Biol Med 2005; 38: 1080-1092. 